\title{
Vitamin D3 differentially regulates parathyroid hormone/ parathyroid hormone-related peptide receptor expression in bone and cartilage
}

\author{
Norio Amizuka, ${ }^{1}$ Mei Yee Kwan, ${ }^{2}$ David Goltzman, ${ }^{2,3}$ Hidehiro Ozawa, ${ }^{1}$ \\ and John H. White ${ }^{2}$ \\ ${ }^{1}$ Department of Oral Anatomy, Niigata University School of Dentistry, Niigata 951-8514, Japan \\ ${ }^{2}$ Departments of Physiology and Medicine, McGill University, Montreal, Quebec H3G 1Y6, Canada \\ ${ }^{3}$ Calcium Research Laboratory, Royal Victoria Hospital and McGill University, Montreal, Quebec H3A 1A1, Canada \\ Address correspondence to: Norio Amizuka, 1st Department of Oral Anatomy, Niigata University School of Dentistry, 5274, 2-Bancho, \\ Gakkoucho-Dori, Niigata 951-8514, Japan. Phone: 81-25-227-2814; Fax: 81-25-227-0804; E-mail: amizuka@dent.niigata-u.ac.jp
}

Received for publication March 4, 1998, and accepted in revised form December 18, 1998.

\begin{abstract}
Transcription of the mouse parathyroid hormone (PTH)/PTH-related peptide (PTHrP) receptor (PTHR) gene is controlled by promoters P1 and P2. We performed transcript-specific in situ hybridization and found that $\mathrm{P} 2$ is the predominant promoter controlling PTHR gene expression in bone and cartilage. Treatment with 1 $\alpha, 25$-dihydroxyvitamin D3 (D3) in vivo specifically downregulated P2-specific transcripts in osteoblasts, but not in chondrocytes, under conditions where it enhanced bone resorption. Treatment of the osteoblastic cell line MC3T3-E1 with D3 in vitro reduced expression of both P2-specific transcripts and PTHR protein. This effect was not blocked by cycloheximide, indicating that D3 inhibits PTHR expression by downregulating transcription of the P2 promoter. A similar inhibitory effect of D3 was not observed in the chondrocytic cell line CFK2. Gene-transfer experiments showed that P2, but not P1, is active in both MC3T3-E1 and CFK2 cells, and that D3 specifically inhibited P2 promoter activity in MC3T3-E1, but not in CFK2 cells. Inhibition of P2 activity by D3 required promoter sequences lying more that $1.6 \mathrm{~kb}$ upstream of the $\mathrm{P} 2$ transcription start site. Thus, the P2 promoter controls PTHR gene expression in both osteoblasts and chondrocytes. D3 downregulates PTHR gene transcription in a cell-specific manner by inhibiting P2 promoter activity in osteoblasts, but not in chondrocytes.
\end{abstract}

J. Clin. Invest. 103:373-381 (1999).

\section{Introduction}

Calcium homeostasis is largely controlled by the action of parathyroid hormone (PTH) and the secosteroid $1 \alpha, 25$ dihydroxyvitamin D3 (D3). PTH is secreted by the parathyroid gland in response to a reduction in extracellular fluid calcium and mobilizes calcium from bone, stimulating its reabsorption in the kidney $(1,2)$. D3 also stimulates bone resorption and calcium release from bone and enhances calcium absorption in the intestine (3-5). D3 has been shown to downregulate expression of PTH in the parathyroid glands $(6,7)$, whereas PTH promotes formation of active D3 by stimulating expression of $1 \alpha$ hydroxylase activity in the kidney, converting the inactive 25 -hydroxy precursor to the active $1 \alpha, 25$-dihydroxy form of D3 (8). PTH-related peptide (PTHrP) was first identified as a factor that mimics the action of PTH when overexpressed by a number of tumors (9-12). PTHrP is important for normal skeletal development (13-17) and stimulates differentiation of a number of cell types (18-23), in addition to other physiological functions (24-28). In contrast to PTH, PTHrP is widely expressed both in the fetus and the adult and acts in a paracrine or autocrine manner under physiological conditions (29-31).

The $\mathrm{NH}_{2}$-terminal regions of PTH and PTHrP are partially conserved and are postulated to form similar helixturn-helix structures. The conserved $\mathrm{NH}_{2}$-terminal regions of PTH and PTHrP interact with the same guany- lyl nucleotide-binding $(\mathrm{G})$ protein-coupled receptor (PTHR) (32). The PTHR is widely expressed, with the highest levels being found in kidney and bone (33). The mouse gene encoding the PTHR is composed of at least 17 exons, and its expression is regulated by at least two promoters $(34,35)$, which give rise to two transcripts that differ in their $5^{\prime}$ untranslated sequences, but not in their coding regions. Transcripts from the upstream mouse promoter (P1) contain sequences derived from two $5^{\prime}$ untranslated region exons, $\mathrm{U} 1$ and $\mathrm{U} 2$, and are highly expressed in kidney and weakly expressed in liver. The downstream mouse promoter (P2) is widely active and gives rise to transcripts containing $5^{\prime}$ untranslated sequences derived from exon U3. The combined length of exons $\mathrm{U} 1$ and $\mathrm{U} 2$ is similar to that of $\mathrm{U} 3$, which accounts for the detection in most tissues of a single mRNA of 2.3 $\mathrm{kb}$. However, larger and smaller exons in RNA species have been detected with PTHR cDNA probes in kidney, liver, brain, skin, and testes (33). Whether these species encode distinct gene products has not been determined. Function of P1 accounts for $80 \%-90 \%$ of renal PTHR gene transcripts. P1-specific transcripts are found at moderate levels in tubular epithelial cells of the nephron and in glomerular podocytes and at high levels in peritubular endothelial cells and in renal vascular smooth muscle (36). In contrast, $\mathrm{P} 2$ activity is restricted to tubular epithelial cells (36). 

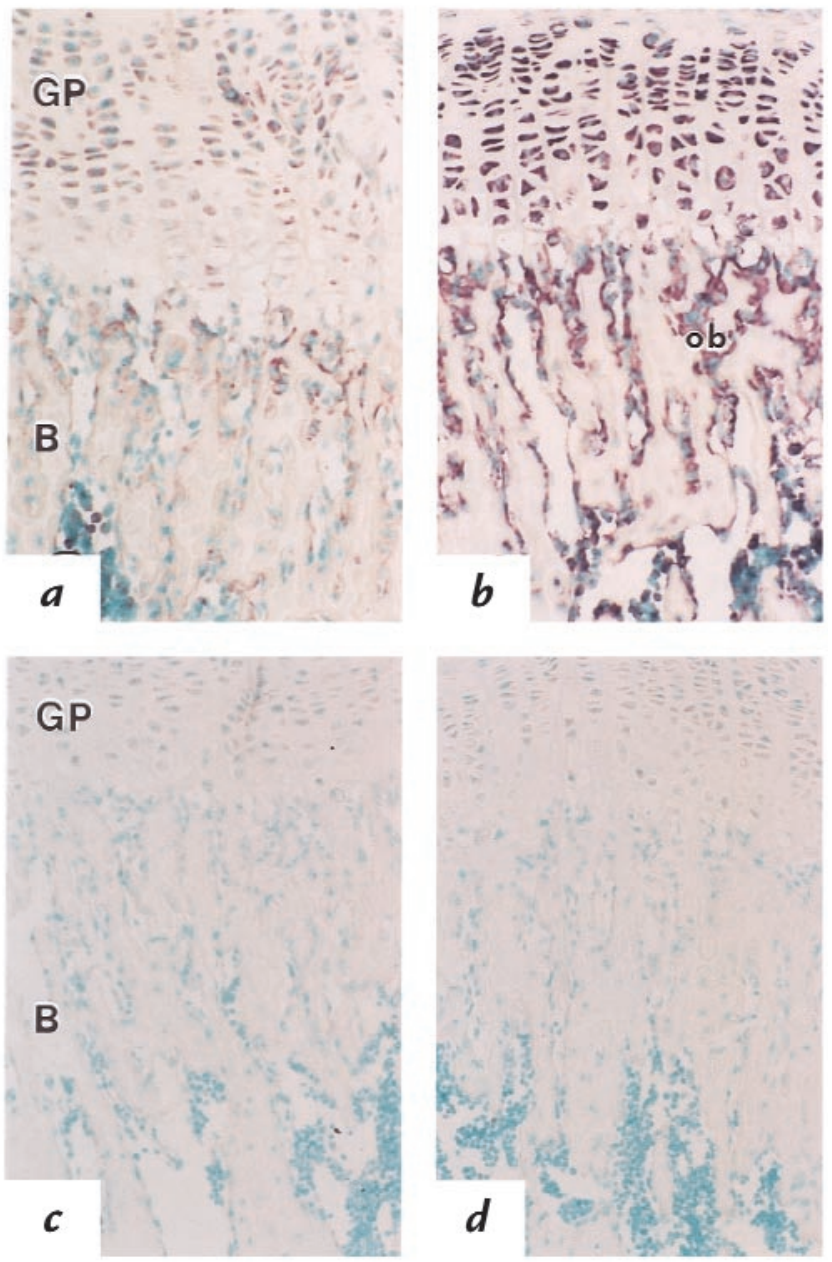

\section{Figure 1}

In situ hybridization demonstrating expression of $\mathrm{P} 1$ - and $\mathrm{P} 2$-specific transcripts in bone and cartilage of mouse tibia. (a) Weak expression of the $\mathrm{P} 1$-specific probe (brown color) is observed in osteoblasts located on bony trabeculae below the epiphyseal growth plate $(G P)$, and in chondrocytes in the proliferative zone and upper region of the hypertrophic zone of the growth plate. (b) Intense P2-specific expression (brown color) was detected in numerous osteoblasts $(o b)$ lining bony spicules in the metaphysis, in chondrocytes in the proliferative zone, and in the upper region of the hypertrophic zone of the growth plate $(G P)$. Control experiments using sense probe for $\mathrm{P} 1$-specific $(\boldsymbol{c})$ and $\mathrm{P} 2$-specific $(\boldsymbol{d})$ transcripts showing no hybridization signals. $a$ and $b, \times 120 ; c$ and $d, \times 80$. $B$, bone.

In this study, we have examined the tissue distribution and promoter specificity of PTHR gene expression in bone and cartilage. We find that $\mathrm{P} 2$ is the predominant PTHR promoter in both bone and cartilage and that expression of the PTHR gene is inhibited by D3 in bone, but not in cartilage, through downregulation of $\mathrm{P} 2$ activity. Given that the D3 receptor (VDR) is expressed in both osteoblasts and chondrocytes, our results suggest that the inhibitory effect of D3 on PTHR gene expression requires tissue-specific transcriptional repressors expressed in bone, but not in cartilage.

\section{Methods}

Administration of D3 to mice and treatment of MC3T3-E1 cells in culture. D3 (Chugai Pharmaceutical Co., Tokyo, Japan) was inject- ed peritoneally into 5-week-old male ddY mice (Nihon SLC Co., Hamamatsu, Japan) at a concentration of $10^{-7} \mathrm{M}$ D3 per animal three times a day for 2 days. Mice were then perfused with $4 \%$ paraformaldehyde in $0.1 \mathrm{M}$ phosphate buffer ( $\mathrm{pH}$ 7.4) through the left ventricle, and tibiae were immersed in the same fixative for $7-9 \mathrm{~h}$ at $4^{\circ} \mathrm{C}$. In control experiments, diluent was injected instead of D3. The murine osteoblastic cell line MC3T3-E1 (Riken Cell Bank, Ibaraki, Japan) were cultured with $\alpha$-MEM (Flow Laboratories, Irvine, Scotland) containing 10\% FCS to $70 \%$ confluency. They were then cultured with $\alpha$-MEM containing $10 \% \mathrm{FCS}$ and $10^{-7} \mathrm{M} \mathrm{D} 3$, in the absence of phenol red, for $24 \mathrm{~h}$. In control experiments, MC3T3-E1 cells were cultured with $\alpha$-MEM containing 10\% FCS without D3 and phenol red.

Reverse transcription-PCR amplification of PTHR and glyceraldebyde3-phosphate dehydrogenase transcripts. MC3T3-E1 cells were cultured as described above, and CFK2 cells were cultured in Roswell Park Memorial Institute (RPMI)-1640 media supplemented with $10 \%$ FCS and $10 \mathrm{mM}$ HEPES. Total RNA was extracted by Trizol reagent (GIBCO BRL, Tokyo, Japan) from tibiae of D3-treated or normal mice and from treated or untreated MC3T3-E1 and CFK2 cells. Then, $5 \mu \mathrm{g}$ of total RNA was reverse-transcribed using Superscript II (GIBCO BRL). PCR reactions $(50 \mu \mathrm{l})$ contained $5 \mu \mathrm{l}$ of $10 \times$ reaction buffer, $1 \mu \mathrm{l}$ of 25 pmol of each primer, $1 \mu \mathrm{l}$ of $10 \mathrm{mM}$ of dNTPs mixture, $1 \mathrm{U}$ of Taq polymerase, $3 \mu \mathrm{l}$ of $25 \mathrm{mM} \mathrm{MgCl}_{2}$, and $2 \mu \mathrm{l}$ of reverse transcription (RT)-DNA and sterile distilled water. Amplification was performed according to Suda et al. (37), with denaturation of $94^{\circ} \mathrm{C}$ for $1 \mathrm{~min}$, annealing at $55^{\circ} \mathrm{C}$ for $1 \mathrm{~min}$, and extension at $72^{\circ} \mathrm{C}$ for $1 \mathrm{~min}$, using a control system PC-700 (ASTEL, Tokyo, Japan). PCR transcripts were electrophoresed in a $1 \%$ agarose gel. A 454-bp fragment of mouse PTHR and a 415-bp fragment of mouse glyceraldehyde-3-phosphate dehydrogenase (GAPDH) were amplified using primers reported by Suda et al. (37) and Tso et al. (38), respectively. For analysis of the effect of cycloheximide on D3-dependent inhibition, CFK2 and MC3T3E1 cells were seeded in $10-\mathrm{cm}$ dishes at $10^{4}$ cells $/ \mathrm{cm}^{2}$ and cultured for 2 days. Cells were then washed once with PBS before addition of appropriate media and stripped serum. Cells were treated with $0.1 \%$ ethanol (vehicle), $100 \mathrm{nM} \mathrm{D3}$, and/or $200 \mathrm{nM}$ cycloheximide as indicated for $24 \mathrm{~h}$ before harvest of RNA. Note that when cells were treated with a combination of D3 with cycloheximide, the latter was added $1 \mathrm{~h}$ before D3 addition.

Western blotting. MC3T3-E1 and CFK2 cells were cultured and treated with D3 and/or cycloheximide as described above. As a positive control, COS-7 cells were cultured and transfected with a VDR expression vector as described (39). Cell pellets were resuspended in lysis buffer (50 mM Tris- $\mathrm{HCl}$ [pH 7.5], 1\% NP40, $150 \mathrm{mM} \mathrm{NaCl}, 1 \mathrm{mM}$ EDTA) containing one tablet per $10 \mathrm{ml}$ of complete protease inhibitors (Boehringer Mannheim, Indianapolis, Indiana, USA), and incubated for $10 \mathrm{~min}$ on ice. Cell debris were collected by centrifugation, and $30 \mu \mathrm{g}$ of each supernatant was loaded on a $10 \%$ SDS polyacrylamide gel. After electrophoresis, proteins were transferred to a Hybond C membrane (Amersham Life Sciences, Buckinghamshire, United Kingdom) and probed by Western analysis using an anti-VDR primary antibody MA1-710 (Affinity BioReagents, Golden, Colorado, USA) and an anti-rat anti-IgG secondary antibody (Boehringer Mannheim), each diluted 1:1,000. Blots were developed by chemiluminescence using the manufacturer's protocol (Du Pont NEN Research Products, Boston, Massachusetts, USA).

Binding assay of ${ }^{125}$ I-labeled [Tyr34] buman PTH(1-34) in MC3T3E1 cells. MC3T3-E1 cells were cultured to $80 \%$ confluency in 24well plates in $\alpha$-MEM supplemented with $10 \%$ FCS. Cells were then incubated overnight using $\alpha$-MEM without FCS. ${ }^{125} \mathrm{I}$ labeled[Tyr34] human PTH(1-34) (Amersham Life Sciences) was diluted with $\alpha$-MEM plus $10 \%$ FCS to $10,000 \mathrm{cpm} / 100 \mathrm{ml}$. Cold human PTH (1-34) $\left(10^{-6}\right.$ to $\left.10^{-11} \mathrm{M}\right)$ was also prepared in 


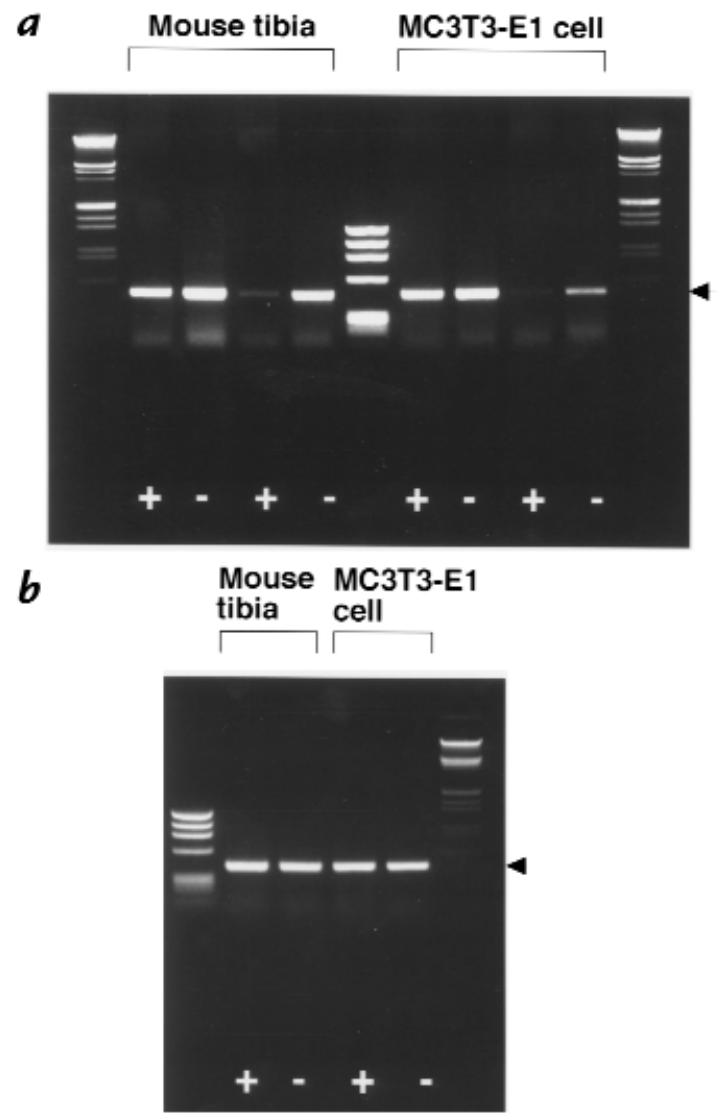

Figure 2

Downregulation of PTHR gene expression in vivo and in vitro by D3. Expression of the PTHR gene ( $\boldsymbol{a}$ ) was detected by RT-PCR as described in Methods. At 25 cycles of amplification, PCR products in control (-) MC3T3-E1 cells and in tibiae are more abundant than those observed after D3 treatment $(+)$. At 40 cycles of amplification, no differences were observed between the PTHR PCR products obtained from control and D3-treated cells. RT-PCR for GAPDH at 20 cycles revealed the same level of gene expression from both control and D3-treated MC3T3-E1 cells and mouse tibiae (b). Arrows in $a$ and $b$ denote the positions of the PCR products of the PTHR and GAPDH genes respectively. GAPDH, glyceraldehyde-3-phosphate dehydrogenase; $P T H R$, parathyroid hormone receptor; $R T$, reverse transcription.

$\alpha$-MEM plus $10 \%$ FCS. Cells were briefly washed twice with $\alpha$ MEM containing $10 \%$ FCS, and then incubated with either ${ }^{125} \mathrm{I}$ labeled PTH alone or a mixture of labeled and unlabeled PTH for $2 \mathrm{~h}$ at $36^{\circ} \mathrm{C}$. Cells were then washed three times with cold PBS, and $1 \mathrm{ml}$ of $1 \mathrm{~N} \mathrm{NaOH}$ was added to each well to recover bound PTH. After $1 \mathrm{~h}$ of incubation, the $\mathrm{NaOH}$ solution was transferred to scintillation vials, and radioactivity was measured by scintillation counting.

In situ bybridization analysis of PTHR coding sequence and P1 and P2 promoter-specific transcripts. Probes complementary to P1- and P2specific transcripts and PTHR coding sequence were generated as described (36). In brief, pU1/U2 was constructed by inserting a 220bp cDNA fragment into Bluescript $\mathrm{SK}^{+}$digested with $\mathrm{Xba} 1$ and Xho1; pU3/170 was constructed by PCR amplification of 170 nucleotides of exon U3 from plasmid PU3A/X. The probes were digested with $A p a \mathrm{I}$ and $\mathrm{XbaI}$, and inserted into the corresponding sites of Bluescript $\mathrm{SK}^{+}$Sense and antisense RNA probes for U1/U2 were obtained by in vitro transcription using T7 or T3 RNA polymerase of $\mathrm{pU} 1 / \mathrm{U} 2$ digested with $\mathrm{XboI}$ or $\mathrm{XbaI}$, respectively, in the presence of digoxigenin-UTP (Boehringer Mannheim). Sense and antisense probes for $\mathrm{U} 3$ were obtained by in vitro transcription of
pU3/170 with ApaI or XbaI, respectively. In situ hybridization was performed using deparaffined sections on poly-L-lysine-coated glass slides treated with $10 \mu \mathrm{g} / \mathrm{ml}$ proteinase $\mathrm{K}$ and $0.2 \mathrm{~N} \mathrm{HCl}$. Acetylation of sections was performed by incubation for $10 \mathrm{~min}$ with $0.25 \%$ acetic anhydride in $0.1 \mathrm{M}$ triethanolamine ( $\mathrm{pH}$ 8.0). A hybridization mixture composed of $50 \%$ formamide, $10 \mathrm{mM}$ Tris$\mathrm{HCl}$ ( $\mathrm{pH}$ 7.6), $100 \mu \mathrm{g} / \mathrm{ml}$ tRNA, $1 \times$ Denhardt's solution, $10 \%$ dextran sulfate, $600 \mathrm{mM} \mathrm{NaCl}, 0.25 \% \mathrm{SDS}$, and $1 \mathrm{mM}$ EDTA was used for hybridization at $50^{\circ} \mathrm{C}$, including each cRNA probe at a concentration of $0.1-1.0 \mu \mathrm{g} / \mathrm{ml}$. After hybridization, nonspecific binding of probes was reduced by RNase A treatment at $37^{\circ} \mathrm{C}$ for 30 $\mathrm{min}$. Detection of signals was performed with antibody to digoxigenin, then made visible with nitroblue tetrazolium salt and 5bromo-4-chloro-3-indolylphosphate.

Immunocytochemistry for the PTHR, and TNAPase and TRAPase enzyme histochemistry. Dewaxed-paraffin sections were pretreated with $1 \%$ BSA in PBS (1\% BSA-PBS) for $30 \mathrm{~min}$, followed by incubation overnight at $4{ }^{\circ} \mathrm{C}$ with rabbit antiserum $1 \mathrm{~K}$-XX1-89 against PTHR $(15,36)$ at a dilution of 1:200. Sections were then incubated with horseradish peroxidase (HRP)-conjugated goat anti-rabbit IgG (Calbiochem-Novabiochem Corp., San Diego, California, USA) at a dilution of 1:100 overnight at $4{ }^{\circ} \mathrm{C}$. For immunostaining of tissue nonspecific alkaline phosphatase (TNAPase), paraffin sections were incubated with rabbit serum to TNAPase (40) after pretreatment with $1 \%$ BSA-PBS for $30 \mathrm{~min}$. Sections were then incubated with HRP-conjugated goat anti-rabbit IgG at a dilution of 1:100 overnight at $4^{\circ} \mathrm{C}$. Sections were viewed using diaminobenzidine (DAB) substrate under light microscopic observation. For tartrate-resistant acid phosphatase (TRAPase) staining, specimens were rinsed with PBS and incubated in a mixture of $8 \mathrm{mg}$ of naphthol AS-BI phosphate (Sigma Chemical Co., St-Louis, Missouri, USA), $70 \mathrm{mg}$ of red violet LB salt (Sigma Chemical Co.), and 50 $\mathrm{mM} \mathrm{L}(+)$-tartaric acid (0.76 g; Nacalai Tesque, Kyoto, Japan) diluted in $0.1 \mathrm{M}$ sodium acetate buffer ( $\mathrm{pH}$ 5.0) for $15 \mathrm{~min}$ at $37^{\circ} \mathrm{C}$. Sections were faintly counterstained with methyl green.

Quantitation of osteoclasts and preosteoclasts between control and D3-treated mice. Quantitative assessment of osteoclasts and preosteoclasts was performed by counting cells between $2.5 \mathrm{~mm}$ from the chondro-osseous junction and the diaphysis surrounding cortical bones on both sides. Histological sections $(n$ $=15$ ) of D3-treated and control animals were examined. Statis-

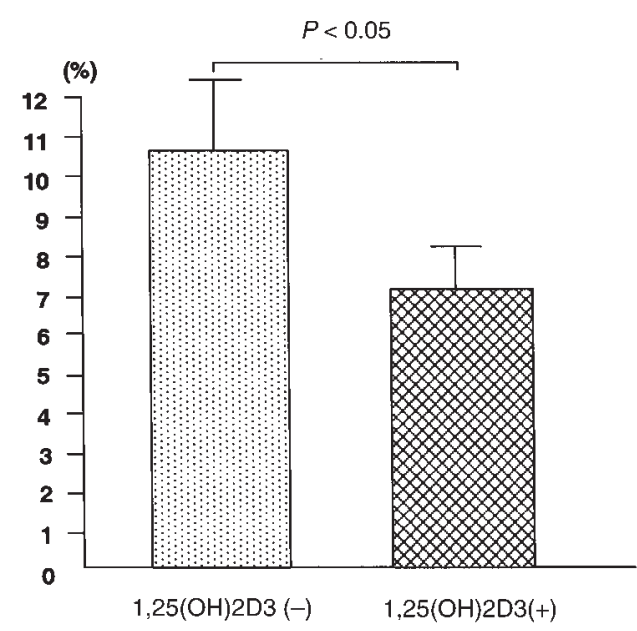

\section{Figure 3}

Binding assay of PTH with MC3T3-E1 cells using ${ }^{125}$-labeled[Tyr34] human PTH(1-34) diluted with $\alpha$-MEM plus $10 \%$ FCS. D3 significantly reduced ${ }^{125}$-human PTH(1-34) binding to MC3T3-E1 cells $(P<0.05)$. Index of PTH binding was represented as percentage of cell-derived cpm divided by total cpm of the medium. PTH, parathyroid hormone. 

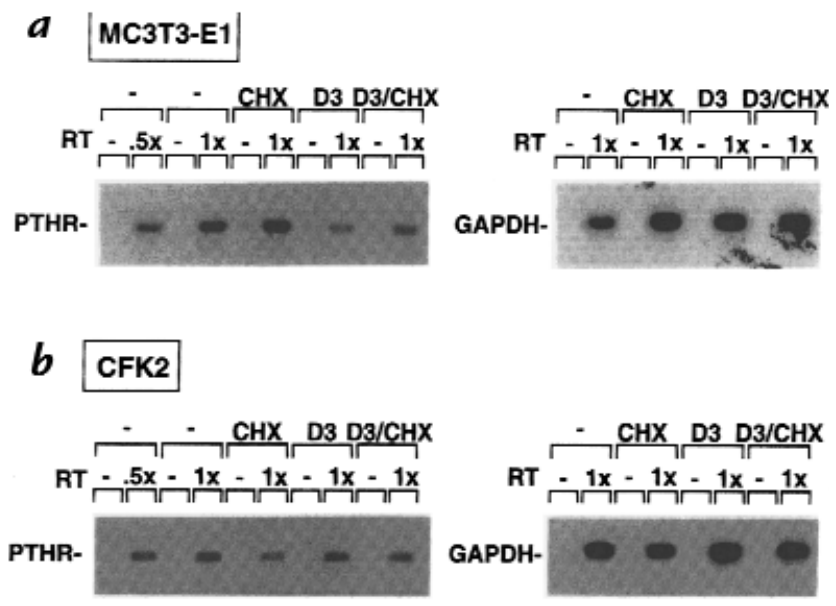

c

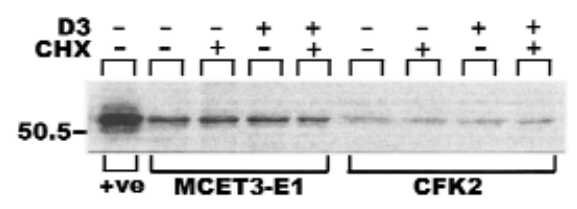

\section{Figure 4}

Downregulation of PTHR gene expression by D3 in MC3T3-E1 cells is not blocked by cycloheximide. (a) Expression of PTHR and GAPDH transcripts were analyzed by RT-PCR in untreated MC3T3-E1 cells (-), or in cells treated with $\mathrm{CHX}, \mathrm{D} 3$, or D3 and $\mathrm{CHX}$ in combination as indicated. Controls were run with $0.5 \times$ volumes of $\mathrm{RT}$ reactions to demonstrate that amplifications were in the linear range. (b) RT-PCR analysis of RNA from CFK2 cells similar to that shown in $a$. PCR products were detected by Southern analysis using the internal sequences $5^{\prime}$-CAAGGACGATGGATTCCTTAACG-3' for PTHR gene and 5'-AGGTCATCCATGACAACTTTG-3' for GAPDH. (c) Control Western analysis of VDR expression levels in treated and untreated MC3T3-E1 and CFK2 cells. Extracts of transiently transfected COS-7 cells were used as a positive control for VDR expression. The position of the 50.5-kDa ovalbumin marker (BioRad Laboratories Inc., Mississauga, Ontario, Canada) is indicated. See Methods for details. CHX, cycloheximide; VDR, D3 receptor.

tical analysis was performed by the Student's $t$ test. Preosteoclasts were identified as mononuclear cells positive for TRAPase staining, while osteoclasts were identified as TRAPase-positive cells possessing more than two nuclei.

Reporter plasmids and transient transfections. The promoter-less pXP2 has been described (41). The plasmid pP1 $1_{2.3}$ contains a 2.3 $\mathrm{kb} B a m \mathrm{HI}-\mathrm{P} v u \mathrm{II}$ fragment of $\mathrm{P} 1$ inserted in the polylinker of pXP2. The plasmids pP2 $2_{1.6}$ and pP2 $2_{6.0}$ contain $1.6 \mathrm{~kb}$ and $6.0 \mathrm{~kb}$ KpnI-BamHI and BamHI-BamHI fragments, respectively, of the $\mathrm{P} 2$ promoter region inserted in the polylinker of $\mathrm{pXP} 2$. The $\beta$ galactosidase reporter plasmid VDRE3-lacZ contains three copies of the mouse osteopontin gene vitamin D3 response element derived from VDRE3tkCAT (39) placed upstream of a minimal promoter from the $h s p 68$ gene. The $\beta$-galactosidase reporter p610AZ, used as an internal control with luciferase reporter plasmids, has been described (42). The plasmid pXP2$\mathrm{tk}$, which contains a truncated herpes simplex virus thymidine kinase promoter inserted in the polylinker of pXP2, was used as an internal control with VDRE3-lacZ. MC3T3-E1 cells were cultured as described above. Media was changed every 3 days. Cells were passaged before they reached confluency. Twentyfour hours before transfection, cells were seeded in $3.5-\mathrm{cm}$ dishes at $10^{5}$ cells per dish and $2 \times 10^{5}$ cells per dish for MC3T3-E1 and CFK2, respectively. For each transfection, $1.5 \mu \mathrm{g}$ of reporter plasmid, $0.5 \mu \mathrm{g}$ of internal control plasmid, and $5 \mu \mathrm{l}$ of Lipofectamine (GIBCO BRL) were used according to the manufacturer's instructions. Twenty-four hours after transfection, media was changed to $\alpha-M E M / 10 \%$ stripped FCS and RPMI1640/10 mM HEPES/10\% stripped FCS for MC3T3-E1 and CFK2, respectively. Transfected cells were treated with $0.1 \%$ ethanol (vehicle) or $100 \mathrm{nM} \mathrm{D} 3$ for $24 \mathrm{~h}$. Cells were then washed once with PBS and harvested with $200 \mu \mathrm{l}$ of $1 \times$ Promega lysis buffer per $3.5-\mathrm{cm}$ dish. Assays for $\beta$-galactosidase were as described (39). Luciferase assays were performed with $25 \mu \mathrm{l}$ of cell lysates in $75-\times 12$-mm tubes (Sarstedt, Newton, North Carolina, USA). After lysates had reached room temperature, $75 \mu \mathrm{l}$ of luciferase reagent (Promega Corp., Madison, Wisconsin, USA) was added to each tube. Activity was determined by EG\&G Berthold Lumat LB 9506 luminometer (Bad Wildbad, Germany).

\section{Results}

Expression of P1- and P2-specific transcripts in bone and cartilage. We were interested in determining the pattern of P1 and $\mathrm{P} 2$ promoter activities in bone and cartilage, which are major target tissues of both PTH and PTHrP. In situ hybridization with an antisense probe recognizing P1specific transcripts revealed only weak signals in both osteoblasts and chondrocytes (Fig. 1a). This is in contrast to the strong P1-specific signals detected in kidney (36). Conversely, the downstream promoter P2 is highly expressed both in growth plate chondrocytes and in osteoblasts lining the bony trabeculae (Fig. 1b). Activity was also detected in many cells in bone marrow, emphasizing that $\mathrm{P} 2$ is the predominant promoter in many cell types. Control experiments using sense probes for P1and P2-specific transcripts did not show hybridization signals (Fig. 1, $c$ and $d$ ). These data extend our previous RNase protection experiments, which suggested that P1 expression is mainly restricted to kidney, whereas P2 expression is widespread (35).

Cell-specific regulation of PTHR gene expression by D3. PTH and D3 are major hormones controlling extracellular fluid calcium concentrations, and interplay between the two hormones is complex. Previous work showed that D3 can downregulate PTH gene expression in the parathyroids $(6,7,43)$. Given that bone is a major site of action of both PTH and D3, it was interesting to determine if D3 modulated the expression of PTHR in bone. We analyzed the effect of D3 on PTHR gene expression in vivo and in vitro using RT-PCR analysis of PTHR transcripts from the mouse tibia and the mouse osteoblast-like cell line MC3T3-E1. Similar to mouse tibia, P2 is the predominant PTHR gene promoter in MC3T3-E1 cells (35). Total RNA isolated from mouse tibiae was subjected to reverse transcription and 25 cycles of amplification with coding sequence-specific primers, which gave rise to lower levels of PCR products from D3-treated animals than from untreated controls. Essentially identical results were obtained with RNA isolated from MC3T3-E1 cells treated with D3 in culture and untreated controls (Fig. 2a). Expression of PTHR transcripts in D3-treated mouse tibia and MC3T3-E1 cells was seen after 40 cycles, which was beyond the linear range. RT-PCR analysis ( 20 cycles) of GAPDH RNA showed that D3 had no effect on GAPDH expression in either mouse tibia or in MC3T3- 

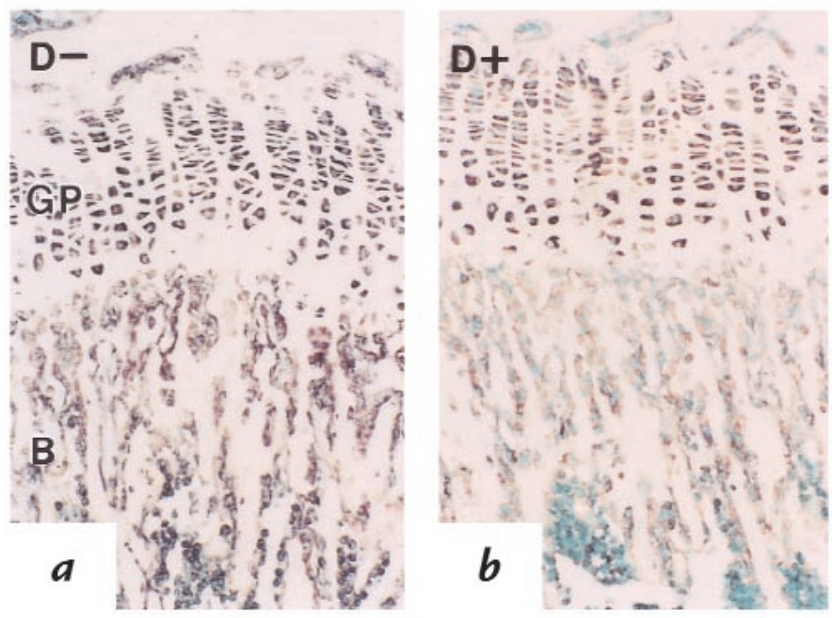

E1 cells (Fig. 2b). Therefore, expression of the PTHR gene was reduced by $\mathrm{D} 3$ both in vivo and in vitro. The regulation of PTHR by $\mathrm{D} 3$ at the protein level was examined by a competitive binding assay of PTH to MC3T3-E1 cells. The results (Fig. 3) show that D3 significantly reduced specific ${ }^{125}$ I-labeled PTH binding to MC3T3-E1 cells ( $P<$ $0.05)$.

The effect of cycloheximide treatment on D3-dependent inhibition of PTHR gene expression was examined in MC3T3-E1 cells. Treatment with cycloheximide alone for 24 hours had no effect on PTHR mRNA levels (Fig. 4a, and data not shown). As expected, reduced levels of PTHR mRNA were detected by RT-PCR in extracts of D3-treated cells. Moreover, the effect of D3 was not abolished by treatment with cycloheximide (Fig. 4a), indicating that D3 acts directly to inhibit PTHR gene expression. We also analyzed the effect of D3 on PTHR gene expression in the rat chondrocyte cell line CFK2 (44). In contrast to MC3T3-E1 cells, D3 did not effect PTHR mRNA levels in CFK2 cells (Fig. $4 b$, and data not shown). Western analyses demonstrated that the VDR expression in both MC3T3-E1 and CFK2 cells was not affected by treatment with D3 and cycloheximide, alone or in combination. These and further experiments (see below) confirmed that both cell lines express functional VDRs. The above in vitro experiments were extended to analyses of PTHR gene expression in mouse tibiae. The distribution of PTHR coding sequences detected in mouse tibiae by in situ hybridization was essentially identical to that of $\mathrm{P} 2$-specific sequences, i.e., in chondrocytes extending from the proliferative zone to the upper region of the hypertrophic zone of the growth plate, and in both preosteoblasts and osteoblasts below the growth plate (Fig 5). This is consis-

\section{Figure 6}

Immunohistochemical analysis of PTHR protein in control ( $\boldsymbol{a}$ and $\boldsymbol{c}$ ) and D3-treated ( $\boldsymbol{b}$ and $\boldsymbol{d}$ ) bone. In $\boldsymbol{a}$ and $c$, PTHR immunoreactivity (brown color) is observed in osteoblasts $(o b)$ and chondrocytes in the growth plate $(G P)$ of control animals. (b) After treatment with D3, immunoreactivity for the PTHR was seen in chondrocytes (arrows) but only weakly in osteoblasts. (d) Under higher magnification, PTHR immunoreactivity in chondrocytes (arrowheads) from D3-treated animals was not altered significantly, whereas immunoreactivity in osteoblasts $(o b)$ was noticeably decreased upon D3 treatment. $a$ and $b, \times 35 ; c$ and $d, \times 140$. $B$, bone.

\section{Figure 5}

In situ hybridization to detect gene expression of the PTHR coding region transcripts in control and D3-treated mouse tibiae. (a) In control tibiae $(D-)$, hybridization signals (dark brown) corresponding to expression of the PTHR coding region were detected in metaphyseal osteoblasts and in chondrocytes of the growth plate $(G P)$. (b) The D3-treated tibia $\left(D^{+}\right)$ showed only a weak hybridization signal (faint brown color) in osteoblasts. Chondrocytes maintained an intense signal, indicating strong PTHR coding region expression in the growth plate. 120x. B, bone.

tent with our previous reports of in vivo binding of PTH and PTHrP to bone and cartilage cells $(15,45-47)$. D3 treatment markedly decreased the expression of the PTHR coding region in both preosteoblasts and osteoblasts. In contrast, growth plate chondrocytes still demonstrated intense expression of the PTHR (Fig. 5).

Immunohistochemistry was performed to examine the effects of D3 in vivo on PTHR protein levels in mouse tibiae (Fig. 6). PTHR immunoreactivity was observed in preosteoblasts and osteoblasts and in chondrocytes of the growth plate. After D3 treatment, immunoreactivity for
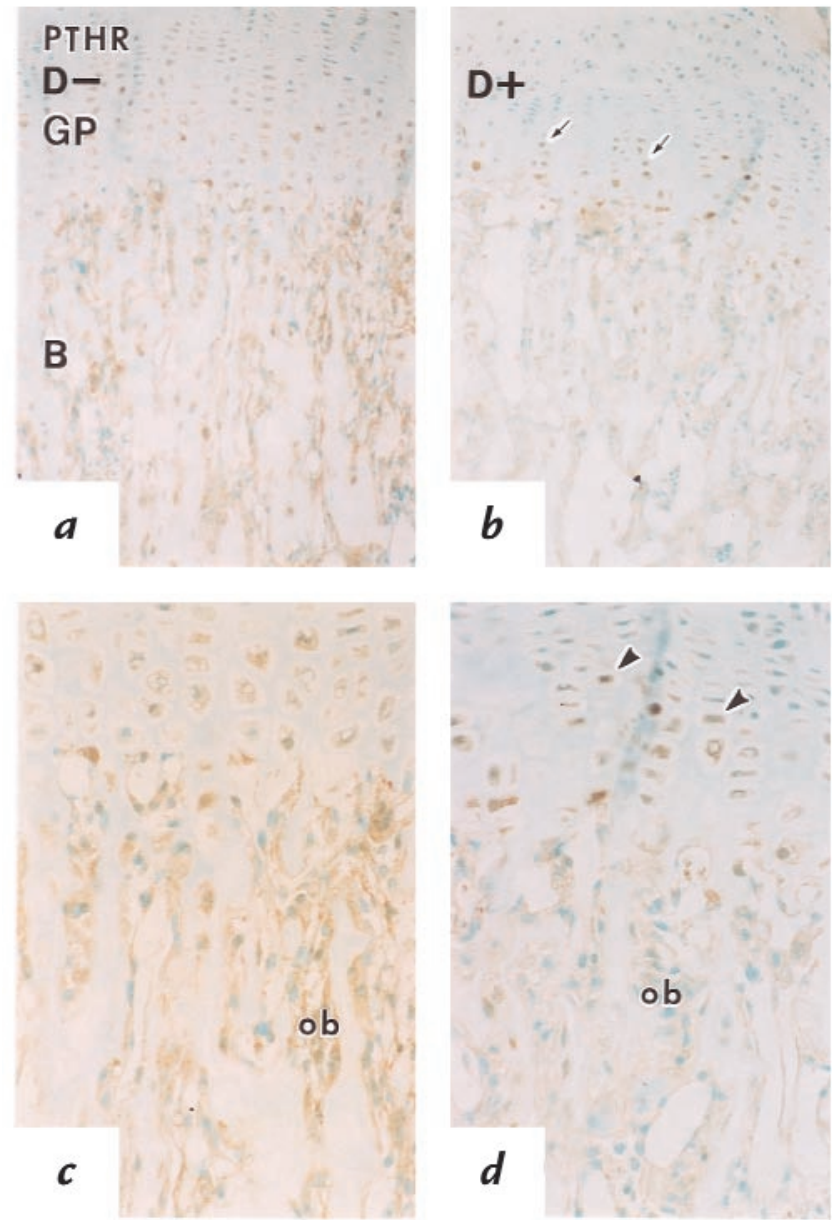

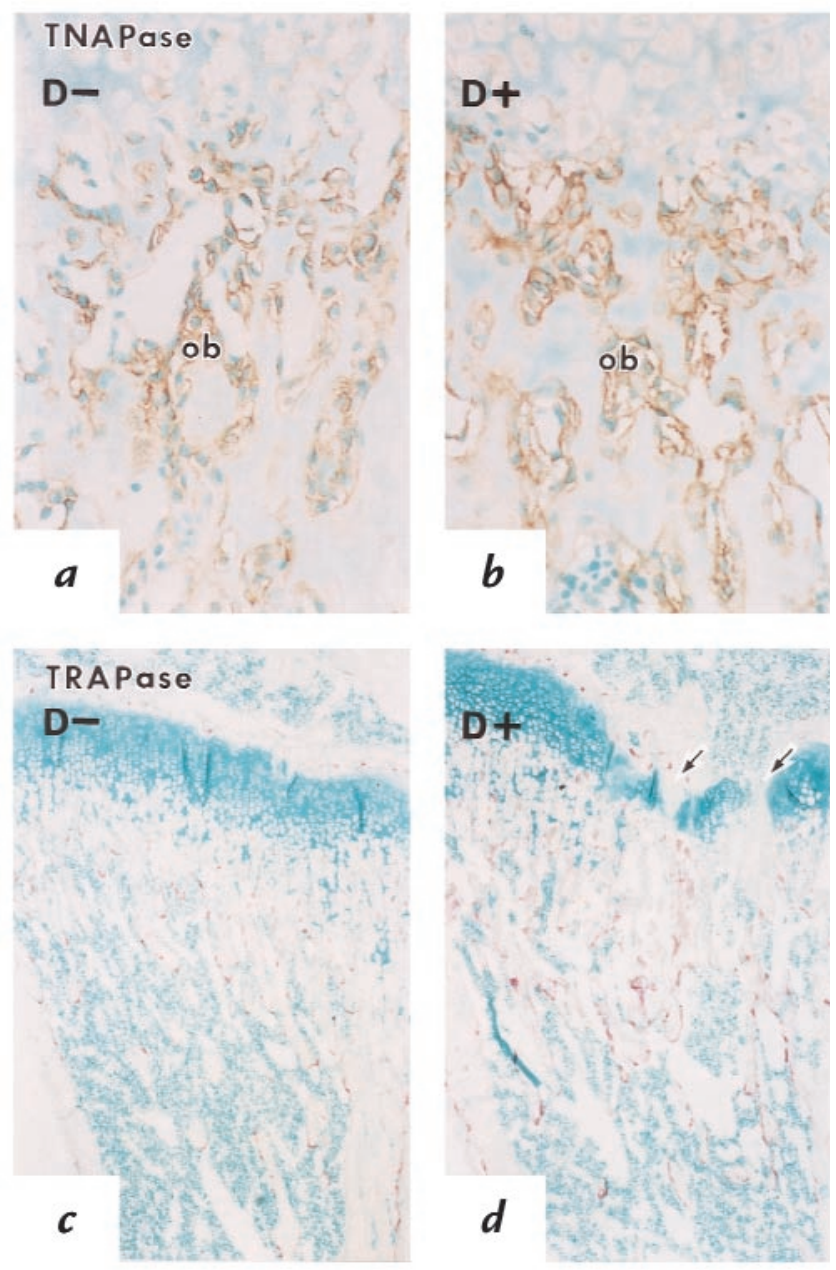

Figure 7

TNAPase immunoreactivity and TRAPase enzyme histochemistry in control and D3-treated tibiae. (a) TNAPase immunoreactivity was observed on the surfaces of osteoblastic cells $(o b) . \times 140$. (b) After D3-treatment of mice $\left(D^{+}\right)$, TNAPase was retained on the osteoblasts. 140×. (c) In tibiae of control mice ( $D-)$ TRAPase-positive osteoclasts (red color) were dispersed over the bony trabeculae. $\times 20$. (d) After D3 treatment $(D+)$, the number of TRAPase-positive osteoclasts increased. Irregular TRAPasepositive cement lines and penetration between the metaphysis and the epiphysis (arrows) was also observed. $\times 20$. TNAPase, tissue nonspecific alkaline phosphatase; TRAPase, tartrate-resistant acid phosphatase.

PTHR persisted in chondrocytes, but was only weakly detected in osteoblasts. Therefore, the distribution of PTHR immunoreactivity after D3 treatment was consistent with the effect of D3 on gene expression that was observed by in situ hybridization. D3 treatment did not diminish TNAPase immunoreactivity on osteoblasts, indicating that the effect of D3 in the osteoblast is selective (Fig 7, $a$ and b). TRAPase-positive osteoclasts increased significantly from $63.14 \pm 5.78$ in controls to $70.00 \pm 7.19$ in D3-treated tibiae $(P<0.05)$, consistent with the effect of D3 on bone resorption. In contrast, the number of preosteoclasts were not significantly affected; $21.57 \pm 3.86$ in controls vs. $23.64 \pm 3.79$ in D3-treated tibiae. Histologically, TRAPase-positive reversal lines and cement lines were increased in the D3-treated tibiae, indicating stimulated osteoclastic activity (Fig. 7, $c$ and d). There was penetration between the epiphysis and metaphysis of D3-treated tibiae, again reflecting enhanced bone resorption. Taken together, these results indicate that D3 downregulates PTHR gene expression in bone, but not in cartilage, under conditions where it enhances bone resorption.

Effect of $D 3$ on $P 2$ promoter usage in bone and cartilage. We next examined, by in situ hybridization, the regulation of expression of $\mathrm{P} 2$-specific transcripts in tibiae of control and D3-treated mice. In keeping with previous results, control mice displayed expression of P2-specific transcripts in both preosteoblasts and osteoblasts, and in chondrocytes in the proliferative zone and the upper hypertrophic zone of the growth plate (Fig. 8a) - a pattern similar to that seen with the PTHR coding region (Fig 5 a). However, reduced expression of P2-specific transcripts in osteoblasts and preosteoblasts, but not in chondrocytes of the growth plate, was observed in D3treated tibiae (Fig. 8b), consistent with repression of PTHR gene transcription from the downstream promoter, P2, in osteoblasts, but not in chondrocytes.

Inbibition of $P 2$ promoter activity by D3 in MC3T3-E1 cells requires upstream sequences. The inhibition of PTHR gene expression by D3 was further investigated in a series of gene-transfer experiments in MC3T3-E1 and CFK2 cells, performed with plasmid recombinants containing P1 or P2 promoter sequences fused to a luciferase reporter gene (Fig. 9a). Control experiments were performed with a synthetic D3-sensitive promoter fused to lacZ (Fig. 9a) to test for VDR function in these cells. Treatment with D3 stimulated lac $Z$ expression to similar levels (three- to fourfold) in both cells lines (Fig. 9b). These results, coupled with the results of Western blotting (Fig. 4), demonstrate the presence of functional VDRs in MC3T3-E1 and CFK2 cells. No expression of luciferase activity above background was observed in either MC3T3-E1 or CFK2 cells transfected with $\mathrm{P} 1_{2.3}$-luc (Fig. 9, $c$ and $d$, lanes 1-4), whereas activity was observed in either cell line transfected with P2 ${ }_{6.0}$-luc or P2 ${ }_{1.6}$-luc recombinants (Fig. 9, $c$ and $d$, lanes 5-8). This is consistent with the relative activities of endogenous $\mathrm{P} 1$ and $\mathrm{P} 2$ promoters in these cells (ref. 35, and data not shown), and with the expression of P2-specific transcripts in bone and cartilage in vivo observed by in situ hybridization. Treatment of CFK2 cells with D3 had no effect on expression of luciferase activity from P1 or P2 (Fig. 9d). In contrast, D3 significantly downregulated luciferase activity expressed in MC3T3-E1 cells transfected with $\mathrm{P} 2_{6.0}$-luc $(P<0.05)$, but not in cells transfected with P2 $2_{1.6}$-luc (Fig. 9b, lanes 5-8), indicating that $\mathrm{D} 3$ represses transcription of the $\mathrm{P} 2$ promoter by acting on upstream promoter sequences. The standard deviations in these experiments were largely due to variations from one independent transfection to another in fold inductions of luciferase activities relative to the low activity of promoter-less control vectors. D3 treatment consistently reduced activity of $\mathrm{P} 2_{6.0}$-luc to an average of 66 $\pm 19 \%$ over four experiments. The magnitude of this effect is in excellent agreement with reduced binding of ${ }^{125} \mathrm{I}$ labeled PTH to D3-treated MC3T3-E1 cells (Fig. 3) and is similar to the degree of D3-dependent downregulation observed on other promoters $(48,49)$. Taken together, 

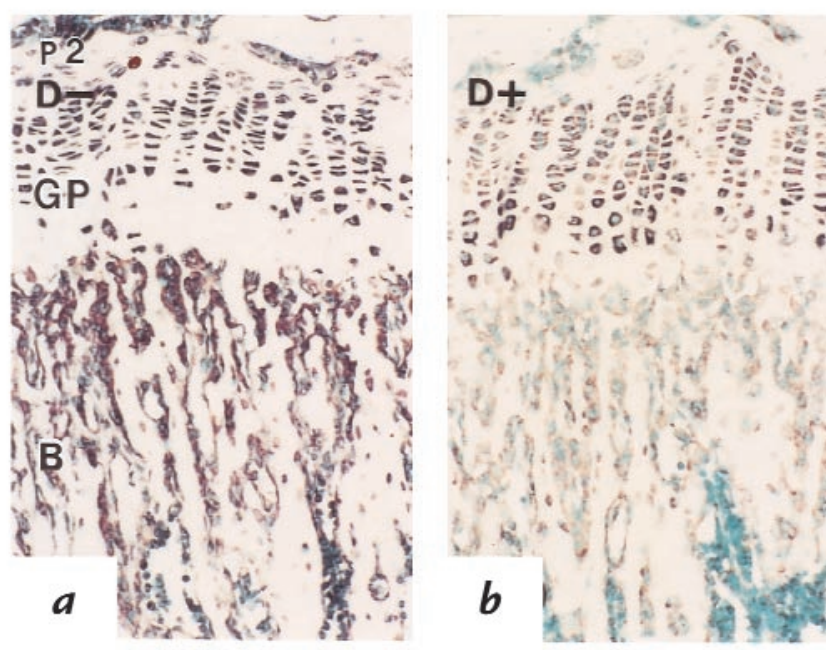

Figure 8

In situ hybridization detecting gene expression of $\mathrm{P} 2$ promoter-specific transcripts in control and D3-treated mouse tibiae. (a) Control tibiae showed strong gene expression of P2-specific transcripts (brown color) in metaphyseal osteoblasts and in chondrocytes of the growth plate $(G P)$. (b) D3-treated tibiae showed reduced expression of P2-specific transcripts in osteoblasts. Strong gene expression was still observed in the growth plate chondrocytes. $\times 120$. B, bone.

our results indicate that $\mathrm{D} 3$ acts to inhibit transcription of the predominant PTHR gene promoter P2 in osteoblasts, but not in chondrocytes, and that this action requires upstream promoter sequences.

\section{Discussion}

The active metabolite of vitamin D3 binds to the nuclear receptor VDR, which is expressed in both osteoblastic cells of bone (50-52) and in cartilaginous cells of the growth plate (53-55). Here we have confirmed that the PTHR is also expressed in osteoblastic cells of bone and in chondrocytes located mainly in the proliferative zone and the upper hypertrophic zone of the growth plate. We have also demonstrated that D3 acts in a cell-specific manner to downregulate the PTHR in osteoblasts, but not in chondrocytes. In bone, D3 enhances resorption and, along with PTH, stimulates the release of skeletal calcium and the maintenance of extracellular calcium homeostasis. In our studies, D3 produced a typical increase in osteoclastic numbers and activity that is responsible for accelerated resorption of bone. The effect of $\mathrm{D} 3$ has been ascribed to an augmented fusion of preosteoclasts to produce multinucleated differentiated osteoclasts $(56,57)$. PTH, PTHrP, and D3 can increase osteoclastic numbers and bone resorption (56-61), apparently through binding of each ligand to their cognate receptors in osteoblastic cells. This stimulates the release-soluble or cell-bound mediators (e.g., cytokines) that enhance preosteoclastic proliferation, differentiation, and/or fusion (62). The D3-induced downregulation of the PTHR in osteoblastic cells that we observed both in vitro and in vivo would be expected to reduce the effectiveness with which PTH or PTHrP enhance osteoclastic activity. The inhibitory effect of D3 on the PTHR in osteoblasts in vivo was selective inasmuch as TNAPase activity was unaffected. Studies in the osteoblastic cell line ROS 17/2.8 have suggested that D3 downregulates the PTHR while increasing expression of osteocalcin (63). D3 is also known to suppress PTH and PTHrP production $(48,49,64)$. Consequently, the downregulation by D3 of both the ligands and their osseous receptors may represent a homeostatic control mechanism designed to limit the bone resorptive and calcium-mobilizing activities that D3 manifests and to prevent excessive increases in extracellular calcium.

D3 is known to modulate proliferation and differentiation of chondrocytes in growth plates as well as to facilitate normal calcification in the cartilage matrix near the chondro-osseous junction $(53,55,65)$. Severe D3 deficiency produces a dyschondroplastic phenotype (rickets) characterized by accelerated chondrocyte proliferation, retarded chondrocyte maturation, and diminished calcification. A very different phenotype results from PTHrP deficiency, which is characterized by diminished chondrocyte proliferation, altered maturation, and premature calcification (13-16). Consequently, although the coordinated action of PTHrP and D3 is necessary, their roles

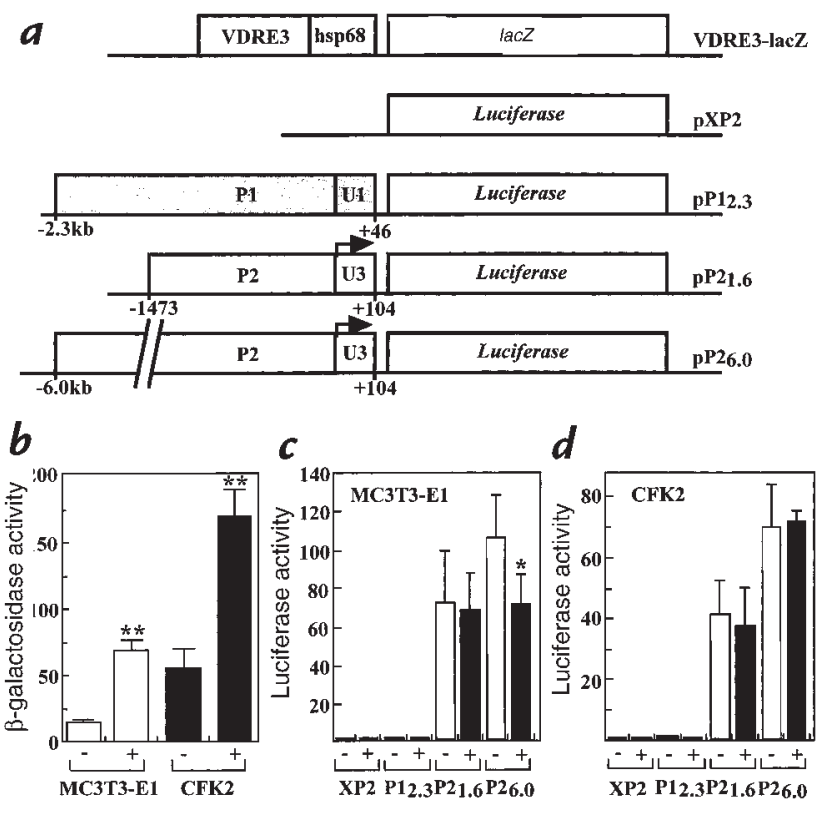

\section{Figure 9}

Downregulation of $\mathrm{P} 2$ promoter activity in MC3T3-E1, but not in CFK2, cells. (a) Promoter reporter recombinants used in this study. (b) MC3T3E1 or CFK2 cells were transiently transfected with VDRE3-lacZ and the tkluc internal control plasmid, and cells were treated with $100 \mathrm{nM} \mathrm{D3}$ as indicated. Activity of $\beta$-galactosidase was normalized to luciferase activity to correct for variations in transfection efficiency. D3 treatment gave rise to a significant increase in $\beta$-galactosidase expression in both MC3T3-E1 and CFK2 cells $\left(n=4 ;{ }^{*} P<0.01\right)$. ( $c$ and $\left.\boldsymbol{d}\right)$ MC3T3-E1 or CFK2 cells were transfected as indicated with luciferase reporter plasmids and p610AZ $\beta$ galactosidase expression as an internal control. Luciferase activities were normalized to $\beta$-galactosidase expression. Cells were treated with $100 \mathrm{nM}$ D3 as indicated. Data are from three to five independent experiments, and standard deviations are indicated. D3 treatment caused a significant repression of luciferase expression in MC3T3-E1 cells transfected with $\mathrm{PP}_{6.0}\left(n=4 ;{ }^{*} P<0.05\right)$. Statistical analyses of paired values were performed using a two-tailed Student's $t$ test. 
in the cartilaginous growth plate are distinct and not overlapping or redundant. The inability of D3 to reduce the efficacy of PTHrP in cartilage, as manifested by lack of downregulation of the PTHR, may therefore reflect the unique complementary roles these two factors subserve in the growth plate. The downstream PTHR promoter, $\mathrm{P} 2$, is clearly the major promoter employed in both bone and cartilage cells and is active in all cell types expressing the receptor (Figs. 1 and 8). Our in vitro studies demonstrated that high levels of luciferase reporter gene activity were expressed under the control of P2, but not P1, sequences in both MC3T3-E1 osteoblastic and CFK2 chondrocytic cell lines (Fig. 9). In contrast, our previous findings showed that P1 activity dominates and drives expression in all cell types expressing the PTHR in kidney, including glomerular podocytes, capillary endothelial cells, vascular smooth muscle, and tubular epithelial cells (36), whereas P2 activity is restricted to tubular epithelial cells. Consequently, the regulation of the renal and osseous expression of the PTHR gene is not tightly coordinated in the mouse.

Our in vitro studies have suggested that D3 reduces PTHR expression in osteoblasts, at least in part, by inhibiting transcription of the P2 promoter from sequences more than $1.6 \mathrm{~kb}$ upstream of the transcription initiation site. The magnitude of the inhibition observed ( $35 \%)$ is similar to the effect of D3 on PTHrP gene transcription observed in gene-transfer experiments (48). The mechanism of D3-dependent transcriptional inhibition is not clear. Studies with the rat PTHrP gene have identified a negative vitamin $\mathrm{D}$ response element (VDRE) composed of directly repeated motifs separated by $3 \mathrm{bp}$ that resemble elements found in genes upregulated by D3 (48). It was suggested that this element binds the VDR as a heterodimer with retinoid $\mathrm{X}$ receptors (RXRs) the same oligomeric combination that binds to upregulatory elements. VDR/RXR heterodimers may act to displace more powerful transactivators to repress, but not eliminate, PTHrP gene transcription. Unlike the PTHrP gene, the negative VDRE in the PTH gene is composed of only a single motif $(43,49)$. Interaction of the VDR expressed in bovine parathyroid extracts with the PTH gene element apparently does not require RXR (64), suggesting that the VDR may bind with a cell-specific negative regulatory factor. In contrast, the negative VDRE in the PTH gene was bound by VDR/RXR heterodimers expressed in rat osteoblast-like cells (64), suggesting that negative regulation of transcription by the VDR in osteoblasts may not occur by the same mechanism as in the parathyroids. Given these results and the findings in our study, it will now be possible to probe the molecular mechanisms controlling the cell-specific inhibition of PTHR gene expression by the VDR in osteoblastic models.

\section{Acknowledgments}

This work was supported in part by the Uehara Memorial Foundation (to N. Amizuka); the Foundation for Total Health Promotion (to N. Amizuka); Ministry of Education, Science and Culture of Japan Grants-in-Aid 08771562 (to N. Amizuka) and 0840756 (to H. Ozawa); Medical Research Council of Canada grants MT-12896 (to J.H. White.) and MT-5775 (to D.
Goltzman.); and by a grant from the National Cancer Institute (to D. Goltzman). J.H. White is a chercheur-boursier of the Fonds de Recherche en Sante du Quebec. M.Y. Kwan is the recipient of a Medical Research Council of Canada Scholarship.

1. Backsai, B.J., and Friedman, P.A. 1995. Activation of latent calcium channels in renal epithelial cells by parathyroid hormone. Nature. 347:388-391.

2. Muff, R., Fischer, J.A., Biber, J., and Murer, H. 1992. Parathyroid hormone receptors in control of proximal tubule function. Annu. Rev. Physiol. 54:67-79.

3. Wasserman, R.H., and Fullmer, C.S. 1983. Calcium transport proteins, calcium absorption and vitamin D. Annu. Rev. Physiol. 45:375-390.

4. DeLuca, H.F. 1985. Vitamin D-dependent calcium transport. Soc. Gen. Physiol. Ser. 39:159-176.

5. Hock, J.M., et al. 1986. Stimulation of undermineralized matrix formation by 1,25-dihydroxyvitamin D3 in long bones of rats. Calcif. Tissue Int. 38:79-86

6. Naveh-Many, T., and Silver, J. 1990. Regulation of parathyroid hormone gene expression by hypocalcemia, hypercalcemia, and vitamin $\mathrm{D}$ in the rat. J. Clin. Invest. 86:1313-1319.

7. Delmez, J.A., et al. 1989. Parathyroid hormone suppression by intravenous 1,25 -dihydroxyvitamin $\mathrm{D}$. A role for increased sensitivity to calcium. J. Clin. Invest. 83:1349-1355.

8. Goltzman, D., and Hendy, G.N. 1995 Parathyroid hormone. In Principles and practice of endocrinology and metabolism. 2nd ed. K.L. Becker, editor. J.B. Lippincott. Philadelphia, PA. 455-467.

9. Burtis, W.J., et al. 1987. Identification of a novel 17,000-dalton parathyroid hormone-like adenylate cyclase-stimulating protein from a tumor associated with humoral hypercalcemia of malignancy. J. Biol. Chem. 161:7151-7156.

10. Kemp, B.E., et al. 1987. Parathyroid hormone-related protein of malignancy: active synthetic fragments. Science. 238:1568-1570.

11. Strewler, G., et al. 1987. Parathyroid hormonelike protein from human renal carcinoma cells: structural and functional homology with parathyroid hormone. J. Clin. Invest. 80:1803-1807.

12. Suva, L.J., et al. 1987. A parathyroid hormone-related protein implicated malignant hypercalcemia: cloning and expression. Science. 237:893-896.

13. Amizuka, N., Henderson, J.E., Warshawsky, H., Goltzman, D., and Karaplis, A.C. 1994. Parathyroid hormone-related peptide-depleted mice show abnormal epiphyseal cartilage development and altered endochondral bone formation. J. Cell. Biol. 126:1611-1623.

14. Amizuka, N., et al. 1996. Haploinsufficiency of parathyroid hormone related peptide (PTHrP) results in abnormal post-natal bone development. Dev. Biol. 175:166-176.

15. Amizuka, N., et al. 1996. Programmed cell death of chondrocytes and aberrant chondrogenesis in mice homozygous for parathyroid hormonerelated peptide (PTHrP) gene deletion. Endocrinology. 137:5055-5067.

16. Karaplis, A.C., et al. 1994. Lethal skeletal dysplasia from targeted disruption of the parathyroid hormone-related peptide gene. Genes Dev. 8:277-289.

17. Weir, E., et al. 1996. Targeted overexpression of parathyroid hormonerelated peptide in chondrocytes causes chondrodisplasia and delayed endochondral bone formation. Proc. Natl. Acad. Sci. USA. 93:10240-10245.

18. Moniz, C., et al. 1990. Parathyroid hormone related peptide in normal human fetal development. Mol. Endocrinol. 5:259-266.

19. Kaiser, S., et al. 1992. Enhanced growth of a human keratinocyte cell line induced by antisense RNA for parathyroid hormone-related peptide. J. Biol. Chem. 267:13623-13628.

20. Kaiser, S., Sebag, M., Rhim, J.S., Kremer, R., and Goltzman, D. 1994. Antisense-mediated inhibition of parathyroid hormone-related peptide (PTHrP) production in a keratinocyte cell line impedes differentiation. Mol. Endocrinol. 8:139-147.

21. van de Stolpe, A., et al. 1993. Parathyroid hormone-related peptide as an endogenous inducer of parietal endoderm differentiation. J. Cell Biol. 120:235-243.

22. Jiang, B., et al. 1995. Role of parathyroid hormone-related protein in the proliferation of vascular smooth muscle cells. Miner. Electrolyte Metab. 21:157-160.

23. Garcia-Ocana, A., et al. 1995. Parathyroid hormone-related protein is an autocrine modulator of rabbit proximal tubule cell growth.J. Bone Miner. Res. 10:1875-1884.

24. Nichols, C.A., Metz, M.A., and Cline, W.H., Jr. 1986. Endothelium-independent linkage of parathyroid hormone receptors of rat vascular tissue with increased adenosine $3^{\prime} 5^{\prime}$-monophosphate and relaxation of vascular smooth muscle. Endocrinology. 119:349-356.

25. Nichols, G.A., Nichols, M.A., and Helwig, J.J. 1990. Binding of parathyroid hormone and parathyroid hormone-related peptide to vascular smooth muscle of rabbit renal microvessels. Endocrinology. 126:721-727.

26. Winquist, R.J., Baskin, E.P., and Vlasuk, G.P. 1987. Synthetic tumorderived human hypercalcemic factor exhibits parathyroid hormone like vasal relaxation in renal arteries. Biochem. Biophys. Res. Commun. 
149:227-232

27. Hongo, T., et al. 1991 Abundant expression of parathyroid hormonerelated protein in primary rat aortic smooth muscle cells accompanies serum-induced proliferation. J. Clin. Invest. 6:1841-1847.

28. Rocacusachs, A., DiPette, D.J., and Nichols, G.A. 1991. Regional and synthetic effects of parathyroid hormone-related protein - preservation of cardiac function and coronary and renal flow with reduced blood pressure. J. Pharmacol. Exp. Ther. 256:110-118.

29. Senior, P.V., Heath, D.A., and Beck, F. 1990. Expression of parathyroid hormone-related protein mRNA in the rat before birth: demonstration by hybridization histochemistry. J. Mol. Endocrinol. 6:281-290.

30. Kramer, S., et al. 1991. Immunological identification and distribution of parathyroid hormone-like protein polypeptides in normal and malignant tissues. Endocrinology. 128:1927-1937.

31. Moseley, J.M., et al. 1991. Immunohistochemical detection of parathyroid hormone-related protein in human fetal epithelia.J. Clin. Endocrinol. Metab. 73:478-484.

32. Jüppner, et al. 1991. A G protein-linked receptor for parathyroid hormone and parathyroid hormone-related peptide. Science. 254:1024-1026.

33. Urena, P., et al. 1993. Parathyroid hormone (PTH)/PTH-related peptide receptor messenger ribonucleic acids are widely distributed in rat tissues. Endocrinology. 133:617-623.

34. McCuaig, K.A., Clarke, J.C., and White, J.H. 1994. Molecular cloning of the gene encoding the mouse parathyroid hormone/parathyroid hormone-related peptide receptor. Proc. Natl. Acad. Sci. USA. 91:5051-5055.

35. McCuaig, K.A., et al. 1995. Parathyroid hormone/parathyroid hormone related peptide receptor gene transcripts are expressed from tissue-specific and ubiquitous promoters. Nucleic. Acids. Res. 23:1948-1955

36. Amizuka, N., et al. 1997. Cell-specific expression of the parathyroid hormone(PTH)/PTH-related peptide receptor gene in rat kidney from kidney-specific and ubiquitous promoters. Endocrinology. 138:469-481.

37. Suda, N., et al. 1996. Expression of parathyroid hormone-related protein in cells of osteoblast lineage. J. Cell. Physiol. 166:94-104.

38. Tso, J.Y., Sun, X.H., Kao, T., Reece, K.S., and Wu, R. 1985. Isolation and characterization of rat and human glyceraldehyde-3-phosphate dehydrogenese cDNA: genomic complexity and molecular evolution of the gene. Nucleic Acids Res. 13:2485-2502.

39. Ferrara, J., McCuaig, K., Hendy, G.N., Uskokovic, M., and White, J.H. 1994. Highly potent transcriptional activation by 16 -ene derivatives of 1,25 -dihydroxyvitamin D3: lack of modulation by 9-cis retinoic acid of response to 1,25-dihydroxyvitamin D3 or its derivatives. J. Biol. Chem. 269:2971-2981.

40. Miki, A., Tanaka, Y., Ogata, S., and Ikehara, Y. 1986. Selective preparation and characterization of membranous and soluble forms of alkaline phosphatase from rat tissues. A comparison with the serum enzyme. Eur. J. Biochem. 160:41-48.

41. Nordeen, S.K. 1988. Luciferase reporter gene vectors for analysis of promoters and enhancers. Biotechniques. 6:454-458.

42. Kothary, R., et al. 1989. Inducible expression of an hsp68-lacZ hybrid gene in transgenic mice. Development. 105:707-714.

43. Demay, M.B., Kiernan, M.S., DeLuca, H.F., and Kronenberg, H.M. 1992. Sequences in the human parathyroid hormone gene that bind the 1,25 dihydroxyvitamin D3 receptor and mediate transcriptional repression in response to 1,25 dihydroxyvitamin D3. Proc. Natl. Acad. Sci. USA. 89:8097-8101.

44. Bernier, S.M, and Goltzman, D. 1993. Regulation of expression of the chondrocytic phenotype in a skeletal cell line (CFK2) in vitro. J. Bone Miner. Res. 8:475-483.

45. Rouleau, M.F., Warshawsky, H., and Goltzman, D. 1986. Parathyroid hormone binding in vivo to renal, hepatic, and skeletal tissues of the rat using a radioautographic approach. Endocrinology. 118:919-931.

46. Rouleau, M.F., Mitchell, J., and Goltzman, D. 1988. In vivo distribution of parathyroid hormone receptors in bone: evidence that a predominant osseus target cell is not the mature osteoblast. Endocrinology. 123:187-191.

47. Rouleau, M.F., Mitchell, J., and Goltzman, D. 1990. Characterization of the major parathyroid hormone target cell in the endosteal metaphysis of rat long bones. J. Bone Miner. Res. 5:1043-1053.

48. Kremer, R., et al. 1996. Identification and characterization of 1,25-dihydroxyvitamin D3-responsive repressor sequences in the rat parathyroid hormone-related peptide gene. J. Biol. Chem. 271:16310-16316.

49. Okazaki, T., Igarashi, T., and Kronenberg, H.M. 1988. 5'-flanking region of the parathyroid hormone gene mediates negative regulation by $1,25-$ $(\mathrm{OH}) 2$ vitamin D3. J. Biol. Chem. 263:2203-2208.

50. Clemens, T.L., et al. 1988. Immuncytochemical localization of the 1,25dihydroxyvitamin D3 receptor in target cells. Endocrinology. 122:1224-1230.

51. Amizuka, N., and Ozawa, H. 1992. Intracellular localization and translocation of $1 \alpha, 25(\mathrm{OH}) 2 \mathrm{D} 3$ receptor in osteoblasts. Arch. Histol. Cytol. 55:77-88.

52. Stumpf, W.E., et al. 1994. 1,25-Dihydroxyvitamin D3 and 22-oxa-1,25dihydroxyvitamin D3 in vivo nuclear receptor binding in developing bone during endochondral and intramembranous ossification. Histochemistry. 102:183-194.

53. Kato,Y., et al. 1990. Role of 1,25-dihydroxycholecalciferol in growth-plate cartilage: inhibition of terminal differentiation of chondrocytes in vitro and in vivo. Proc. Natl. Acad. Sci. USA. 87:6522-6526.

54. Klaus, G., Meinhold-Heerlein, R., Milde, P., Ritz, E., and Mehls, O. 1991. Effect of vitamin D on growth cartilage cell proliferation in vitro. Pediatr. Nephrol. 5:461-466.

55. Schwartz, Z., et al. 1992. Production of 1,25-dihydroxyvitamin D3 and 24,25 -dihydroxyvitamin D3 by growth zone and resting zone chondrocytes is dependent on cell maturation and is regulated by hormones and growth factors. Endocrinology. 130:2495-2504.

56. Takahashi, N., et al. 1988. Osteoclast-like cell formation and its regulation by osteotropic hormones in mouse bone marrow cultures. Endocrinology. 122:1373-1382.

57. Suda, T., Takahashi, N., and Martin, T.J. 1992. Modulation of osteoclast differentiation. Endocr. Rev. 13:66-80.

58. McSheehy, P.M.J., and Chambers, T.J. 1986. Osteoblastic cells mediate osteoclastic responsiveness to parathyroid hormone. Endocrinology. 119:1654-1659.

59. Akatsu, T., et al. 1989. Parathyroid hormone (PTH)-related protein is a potent stimulator of osteoclast-like multinucleated cell formation to the same extent as PTH in mouse marrow cultures. Endocrinology. 125:20-27.

60. Takahashi, N., et al. 1988. Osteoblastic cell are involved in osteoclast formation. Endocrinology. 123:2600-2602.

61. Udagawa, N., et al. 1989. The bone marrow-derived stromal cell lines MC3T3-G2/PA6 and ST2 support osteoclast-like cell differentiation in cocultures with mouse spleen cells. Endocrinology. 125:1805-1813.

62. McSheehy, P.M.J., and Chambers, T.J. 1987. 1,25-Dihydroxyvitamin D3 stimulates rat osteoblastic cells to release a soluble factor that increases osteoclastic bone resorption. J. Clin. Invest. 80:425-429.

63. Xie, L.Y., Leung, A., Segre, G.V., Yamamoto, I., and Abou-Samra, A.-B. 1996. Down-regulation of the PTH/PTHrP receptor by vitamin D3 in the osteoblast-like ROS 17/2.8 cells. Am. J. Physiol. 270:E654-E660.

64. Mackey, S.L., Heymont, J.L., Kronenberg, H.M., and Demay, M.B. 1996. Vitamin D receptor binding to the negative human parathyroid hormone vitamin D response element does not require the retinoid $\mathrm{x}$ receptor. Mol. Endocrinol. 10:298-305.

65. Fraquharson, C., Rennie, J.S., Loveridge, N., and Whitehead, C.C. 1996. In vivo and in vitro effect of 1,25-dihydroxyvitamin D3 and 1,25-dihydroxy-16-ene-23yne-vitamin D3 on the proliferation and differentiation of avian chondrocytes: their role in tibial dyschondroplasia. J. Endocrinol. 148:465-474. 